\title{
DESENVOLMENTO DE LIDERANÇAS COM FOCO EM RESULTADOS
}

\author{
Martins, LPS 1 , Madi, MR 2 , Melo, JC 3 \\ Assistente Técnico de Saúde responsável pelo Planejamento e Gestão do Instituto de Radiologia do HCFMUSP/InRad \\ Diretora Executiva do Instituto de Radiologia do HCFMUSP / InRad \\ Assistente de Planejamento e Gestão do HCFMUSP / InRad
}

\section{Introdução}

Os processos organizacionais constantemente necessitam de transformações e adaptações rápidas e eficazes por parte dos seus líderes para geração de resultados. O exercício de liderança é um elemento muito importante para o sucesso de qualquer organização, pois contempla o processo de execução dos objetivos e metas institucionais.

O Instituto de Radiologia (InRad), desenhou um modelo de exercício de liderança, para gerenciar os resultados de desempenho dos processos assistenciais, denominado: Reuniões de Análises Críticas (RACs). A finalidade das RACs é de monitorar o desempenho dos processos a partir de um bloco de indicadores definidos pela alto administração. Nessa abordagem, foi estabelecido um responsável Médico para cada Unidade produtiva do Instituto e um "Facilitador" de RACs, o qual tem a função de auxiliar o médico da unidade. Chamamos de facilitador a pessoa que coordena, dirige ou organiza as Reuniões de Análise Critica.

\section{Objetivo}

Desenvolver a liderança no desempenho por resultados a partir da institucionalização de Reuniões de Análises Crítica _ RACs e do estabelecimento do Perfil do Facilitador.

\section{Materiais e Métodos}

Através da coordenação pelo Centro de Planejamento e Gestão, foi desenhado o perfil do facilitador de RACs, que tinham as seguintes características: ouvir a equipe, estimular a motivação e proatividade, manter o cronograma atualizado das reuniões, agendar as reuniões e convidar a equipe multidisciplinar, monitorar a execução das análises critica dos indicadores pelos seus responsáveis, complementar as análises dos indicadores com as causas, impacto e ações quando aplicável, estimular a participação de toda equipe durante a Reunião de Análise Crítica, monitorar as ações e planos de melhorias nas RACs e garantir a corresponsabilidade do time nos resultados alcançados.

Foram realizados treinamento com os facilitadores sobre quais os critérios seriam avaliados nas auditorias de análises críticas dos indicadores.

Após o desenho do perfil, foi realizado uma auto avaliação pelos facilitadores, seguida de uma reunião de feedback pela equipe do Centro de Planejamento e Gestão.

\section{Resultados}

Ao longo dos anos, foi possível perceber a evolução no alcance dos objetivos propostos no escopo do perfil dos facilitadores de RACs, bem como melhorias significativas nos critérios avaliados nas auditorias de análise crítica dos indicadores.

\section{Resultados}

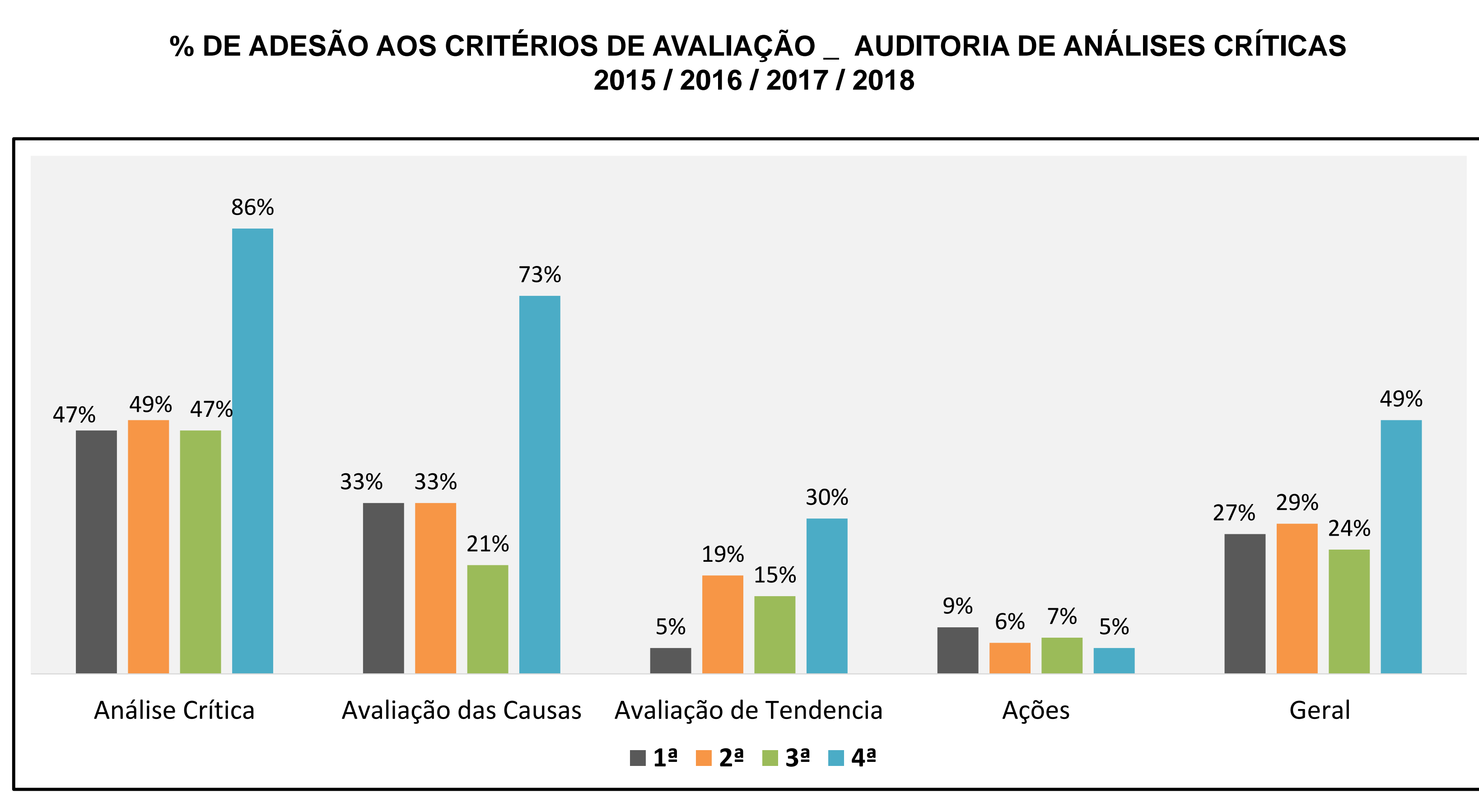

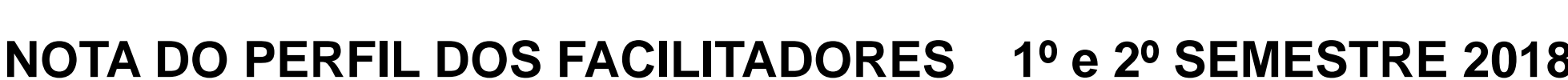

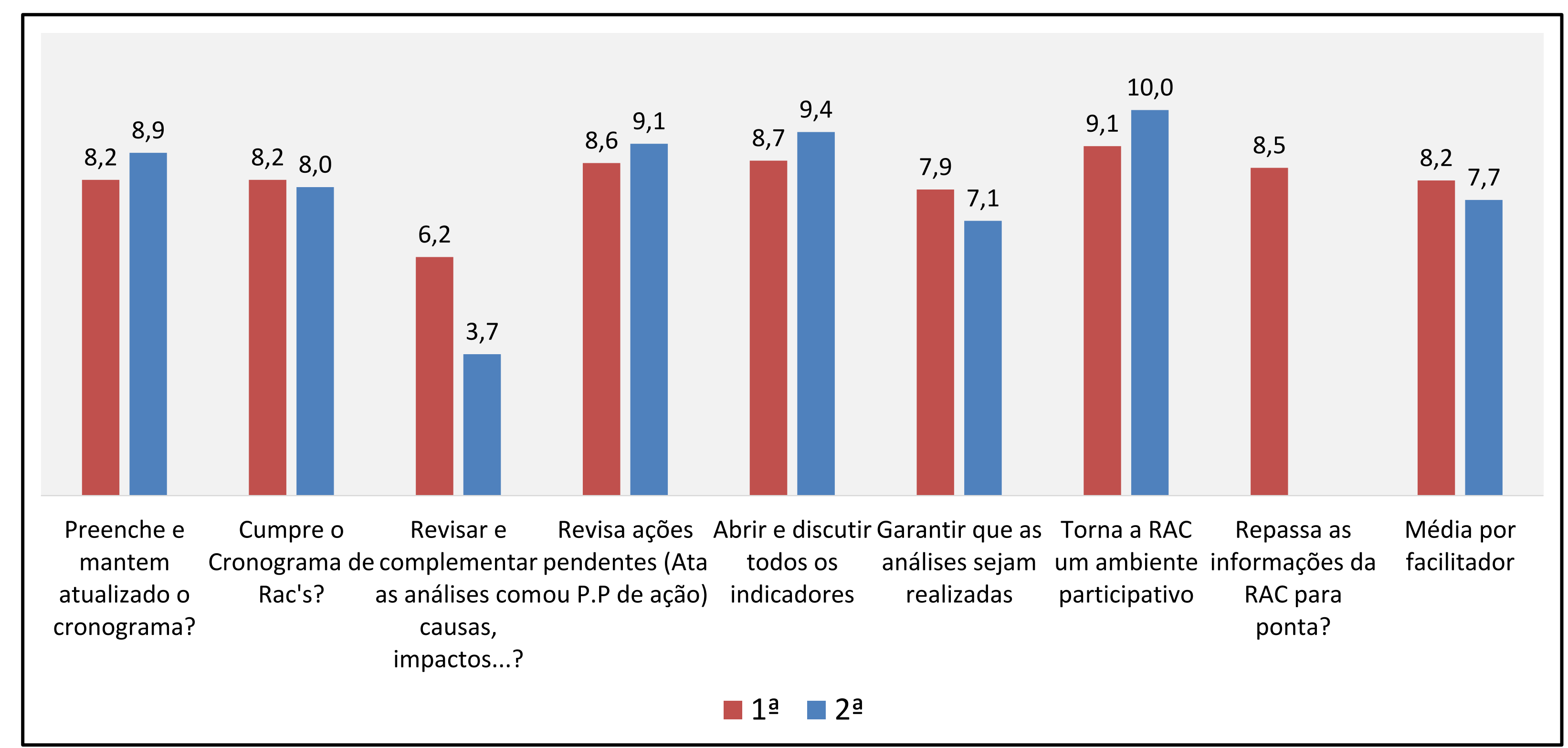

\section{Conclusão}

Conclui-se que com esse resultado, um maior envolvimento da liderança na corresponsabilidade sobre os resultados e metas estabelecidos. Entende-se que a estruturação de Reuniões de Análises Críticas, trouxe grandes resultados para a instituição, pois norteou a equipe no foco em resultados. Contudo, foi possível mostrar à alta administração, a importância da definição de um perfil de liderança que consequentemente trouxe o pertencimento das equipes nos resultados alcançados.

\section{Instituto de Radiologia HCFMUSP}

